\title{
Three-Dimensional Probabilistic Analysis of The Surface Settlement Based On Spatial Variability of Soil Properties: Case Study Zarbalizadeh NATM Tunnel
}

\author{
Mohammad Ali Tahmasebi \\ Azad University: Islamic Azad University \\ Reza Shirinabadi ( $\sim$ R_shirinabadi@azad.ac.ir) \\ Azad University: Islamic Azad University \\ Esmaiel Rahimi \\ Azad University: Islamic Azad University \\ Ehsan Moosavi \\ Azad University: Islamic Azad University \\ Amir Hossein Bangian Tabrizi \\ Azad University: Islamic Azad University
}

\section{Research Article}

Keywords: Random field, Spatial variability, Scale of fluctuation, NATM tunnel, surface settlement

Posted Date: September 15th, 2021

DOI: https://doi.org/10.21203/rs.3.rs-855215/v1

License: (c) (1) This work is licensed under a Creative Commons Attribution 4.0 International License.

Read Full License 


\section{Three-dimensional probabilistic analysis of the surface settlement based on spatial variability of soil properties: case study Zarbalizadeh NATM tunnel}

\section{Abstract}

Designing and the construction of a tunnel in urban areas has their own specific considerations. Usually, excessive settlement caused by tunneling during construction damages the adjacent infrastructures and utilities, especially if the tunnel is excavated by the new Austrian tunneling method (NATM). Thus, it's important to make accurate predictions and effective control on tunneling-induced settlement. In this study, the soil's Young's modulus was modeled using a three-dimensional random field and coupled with a finite difference method (FDM) analysis to reveal the influence of scale of fluctuation (SOF) on the maximum surface settlement $\left(S_{\max }\right)$. To generate the field of soil's Young's modulus, the Fourier series method is employed and sensitivity studies are further performed via Monte-Carlo simulations (MCS). The results demonstrate both the mean value of $S_{\max }$ and its coefficient of variation (COV) increase from 28 $\mathrm{mm}$ to $31 \mathrm{~mm}$ and from 0.02 to 0.35 respectively, with an increasing horizontal SOF but they stabilize at higher values of SOF. Furthermore, the probability of failure increases as COV increases for each allowable limit greater than the verification FDM of $S_{\max }$. It is observed that ignoring the spatial variability of soil's properties leads to an underestimate of the risk of excessive surface settlement.

Keywords: Random field; Spatial variability; Scale of fluctuation; NATM tunnel; surface settlement

\section{Introduction}

The most destructive tunneling impact on the environment is the ground settlement which creates serious problems for the existing buildings and structures along the tunnel alignment (Moosavi et al. 2018). Surface settlement during tunnel excavation has been specially considered due to potential danger to the adjacent structures, infrastructures, establishments, etc. In this regard, the great assessment and real displacement distribution of soil that is the fundamental part in programming, designing and utilizing from the urban tunnels (Marinos et al. 2019). However, it is possible through considering the uncertainty of soil behavior. In the natural condition, soil is horizontally layered by spatial variability at its parameters (Fenton and Griffiths 2005). Soil properties show the severe spatial variations due to sedimentary and sedimentation processes (Dasaka and Zhang 2012). Recently, several researchers have examined the impact of soil variability on the surface settlement due to tunneling (Mollon et al. 2013). Inspected the soil behavior by using one probabilistic method based on three-dimensional limited difference analysis. Parameters related to soil properties and the retaining fluid pressures were modeled as random variables and six failure modes were presented and analyzed (Miro et al. 2015). All of the aforementioned work have led to improve the perception of the uncertainty effect of soil parameters on the ground movements for the sake of tunneling. The characteristic of soil variability in the wide range of geotechnical fields was scrutinized by (Cheng et al. 2019a; Griffiths et al. 2006; Gui and Chen 2013). The results demonstrate that the deterministic solutions for which soil parameters are set to fixed values may vary from the actual performance of geotechnical structures. Uncertainty is caused by different factors such as measurement errors, uncertainty in modeling the soil real behavior and intrinsic changes of soil properties in 
both horizontal and vertical directions (Nadim 2007). The studies conducted by different scientists such as (Sivakumar Babu and Mukesh 2004; Uzielli et al. 2005; Wei et al. 2005) revealed that the effect of uncertainty caused by intrinsic changes in soil properties in two directions of vertical and horizontal governs other factors making uncertainty. In 1997, Vanmarcke (Vanmarcke 1977) measured three parameters including mean, standard deviation and SOF to observe the random behavior of soils in the geotechnical problems. The present research aims to analyze the effect of spatial variability of soil properties and its relation with the $S_{\max }$ in NATM tunneling. It is noteworthy that the effect of spatial variability of soil properties caused by NATM tunneling has not been remarkably mulled over. Young's modulus have the greatest share in soil deformation among soil parameters ( $\mathrm{Li}$ et al. 2015; Vanmarcke 2010), and therefore in this paper the spatial variability of $\mathrm{E}$ was only considered as three-dimensional random fields. As no information has been found about the horizontal SOF for its soil, a parametric analysis of SOF has been done to measure the surface settlement. The paper is structured as follows: first, the main parameters and functions required to generate the random field are explained; second, geological conditions, the excavation method and the support systems of the desired tunnel are described; third, the three-dimensional numerical model is created based on the project conditions and the model is validated. This is followed by applying a random field to the numerical model; Finally, the probability of failure and the reliability index are examined based on the results of the numerical model.

\section{Computational framework}

\subsection{Spatial variability of soil properties}

Spatial variability of soil properties is regarded as one of the most significant sources of uncertainty in the geotechnical problems for the sake of sedimentary processes and after sedimentation (Zhou et al. 2019). The spatial variability of soil properties can be well described in the random field theory framework instead of conventional random variables or random processes (Vanmarcke 2010). The SOF is an indicator applied to measure the correlation of the parameter and it refers to the distance in which parameters related to soil show more correlation. Notably, out of this behavioral range, it reveals a completely random behavior (Jaksa et al. 1997). In other words, if the distance between the two points is less than SOF, the soil properties are highly correlated at these points. If the distance is larger than SOF, the correlation is weak. On the other hand, a slight amount of a huge fluctuation displays that the soil properties in the large spatial scale are highly correlated with each other. Consequently, a smooth random field is obtained. When the SOF value is close to $\infty$, the randomly generated field becomes more unified. SOF estimation has been extensively studied in various papers (Bagińska et al. 2016; Bagińska et al. 2018). On the other hand, the value of the horizontal SOF is usually greater than the vertical mode (Cherubini 1997). Generally, some methods have been developed to estimate the vertical SOF (depth variability), whereas these methods have not been satisfactorily developed for horizontal SOF. Therefore, in the present study, different meaningful values are assumed from SOF in the vertical and horizontal directions. Another important point is that the parametric SOF that depends on the intended parameter measurement distances and its value should be selected according to the dimensions of the problem (Fenton and Griffiths 2002). Young's modulus is considered as key parameter to make a random field because it has the greatest impact on ground settlement among other soil parameters (Phoon and Kulhawy 1999) also, in order to investigate the probabilities of a random field, it is necessary to define a statistical distribution corresponding to the geological 
conditions of the region to examine all possible states. Normal and log-normal distributions are the sample of statistical distributions that are more compatible with the soil physical sedimentary process. Among the two mentioned distributions, log-normal distribution spectrum $(0, \infty)$ is more consistent with the statistical properties of soil parameters. Hence, log-normal distribution usually, rather than normal distribution is used in lack of the geological data. Therefore, in this study, in order to create spatial variability of Young's modulus base on a log-normal distribution function is used (Huang et al. 2013).

\subsection{Generation of random fields}

A variety of approaches are statistically defined to simulate random fields such as average, variance and SOF, because of the lack of field measurements, the following correlation function was employed for the generation of random fields in this study (Griffiths and Fenton 2008)

$$
\rho\left(\tau_{x}, \tau_{y}, \tau_{z}\right)=\exp \left(\frac{-2\left|\tau_{x}\right|}{\theta_{x}}+\frac{-2\left|\tau_{y}\right|}{\theta_{y}}+\frac{-2\left|\tau_{z}\right|}{\theta_{z}}\right)
$$

Where the correlation function $\rho\left(\tau_{\mathrm{x}}, \tau_{\mathrm{y}}, \tau_{\mathrm{z}}\right)=\left(\mathrm{x}_{2}-\mathrm{x}_{1}, \mathrm{y}_{2}-\mathrm{y}_{1}, \mathrm{z}_{2}-\mathrm{z}_{1}\right)$. Parameters $\theta_{\mathrm{x}}, \theta_{\mathrm{y}}$ and $\theta_{\mathrm{z}}$ are SOF in the directions $\mathrm{x}, \mathrm{y}$ and $\mathrm{z}$, respectively. Here, based on one of the pioneering studies (Fenton and Griffiths 2003) random fields that model soil strength parameters are obtained by the appropriate transformation of normal random fields if the Young's modulus is assumed to be a $\log$-normal random field $\mathrm{Y}(\mathrm{x})$ (where $\mathrm{x} \in \mathrm{D}$, where $\mathrm{D}$ is a three-dimensional domain), the transformed field is obtained from a normal random field $\mathrm{X}(\mathrm{x})$ by applying the following transformation (Griffiths and Fenton 2001)

$$
\mathrm{Y}(\mathrm{x})=\exp (\mathrm{X}(\mathrm{x}))
$$

At a specified point $x$, the probability density function of $Y(x)$ takes the following form (Fenton and Griffiths 2003)

$$
f(t)=\left\{\begin{array}{ll}
\frac{1}{t \sigma_{\ln Y \sqrt{2 \pi}}} \exp \left\{-\frac{1}{2}\left(\frac{\ln t-\mu_{\ln Y}}{\sigma_{\ln Y}}\right)^{2}\right\}, & t>0 \\
0, & t \leq 0
\end{array}\right\}
$$

Where parameters $\mu_{\ln Y}$ and $\sigma_{\ln Y}$ are the mean value and the standard deviation of the underlying normal distribution $\mathrm{X}(\mathrm{x})$, respectively. The mean value $\mu_{\mathrm{Y}}$ and the standard deviation $\sigma_{\mathrm{Y}}$ of on the log-normal distribution $\mathrm{Y}(\mathrm{x})$ are related to $\mu_{\ln Y}$ and $\sigma_{\ln Y}$ by

$$
\begin{aligned}
& {[\mathrm{Y}]=\mu_{\mathrm{Y}}=\exp \left(\mu_{\ln \mathrm{Y}}+\frac{1}{2} \sigma_{\ln \mathrm{Y}}^{2}\right)} \\
& \sigma_{\mathrm{Y}}^{2}=\mu_{\mathrm{Y}}^{2}\left(\exp \left(\sigma_{\ln \mathrm{Y}}^{2}\right)-1\right)
\end{aligned}
$$


To consider the range of Young's modulus, Fenton and Griffiths (Fenton and Griffiths 2003; Griffiths and Fenton 2008) suggested the following transformation:

$$
\mathrm{Y}(\mathrm{X})=\mathrm{a}+\frac{1}{2}(\mathrm{~b}-\mathrm{a})\left[1+\tanh \left(\frac{\mathrm{m}+\mathrm{s} \mathrm{X}_{0}(\mathrm{x})}{2 \pi}\right)\right]
$$

Where $\mathrm{X} 0(\mathrm{x})$ is the standard normal random variable, and $\mathrm{m}$ and $\mathrm{s}$ are the distribution's parameters. The Probability density function of $\mathrm{Y}(\mathrm{x})$ takes the form:

$$
f(t)=\left\{\begin{array}{ll}
\frac{\sqrt{\pi}(b-a)}{\sqrt{2} s(t-a)(b-t)} \exp \left\{-\frac{1}{2 s^{2}}\left[\pi \ln \left(\frac{t-a}{b-t}\right)-m\right]^{2}\right\}, & t>0 \\
0, & t \leq 0
\end{array}\right\}
$$

By means of the third-order Taylor's expansion, the following approximation can be obtained:

$$
\sigma_{Y}^{2} \approx \frac{1}{4}(a-b)^{2} \frac{s^{2}}{4 \pi^{2}+s^{2}}
$$

\section{Project Overview}

The Zarbalizadeh underpass project in Tehran has been considered to pass through the corridor subway- railway and join Zarabalizadeh street to Maddah street. Moreover, this underpass is located between the south terminal subway station and Khazaneh subway station. The purpose of executing this project in district 16 of Tehran is to connect the eastern- western parts between two urban areas. In fact, it reduces the traffic and time of commuting in this crowded district. The Zarbalizadeh underpass project is an urban tunnel located in the south of Tehran with an average overburden height of $3.5 \mathrm{~m}$, excavation width of $14.14 \mathrm{~m}$ and height of $11.55 \mathrm{~m}$, respectively. This tunnel with a total length of $44 \mathrm{~m}$ consists of a multi-arc section and was excavated by the NATM method. The analysis and design of this project was based on reliable references such as: FHWA-NHI-10-034, FHWA-NJ-2005-002, AASHTO, ACI 318-05 and the international tunneling and underground space association (ITA) Guidelines for the design of Tunnels. It should be noted that the project was recognized in 2018 by ITA in China as the world's leading tunnel projects (in the section of tunnel projects with a credit of less than 50 million euros). Fig. 1 shows the situation of the project site and Fig. 2 illustrates the cross-section and longitudinal profile of Zarbalizadeh tunnel.

Fig. 1

Fig. 2

\subsection{The geological engineering conditions}

The soil layers of the tunnel route (Table 1) are divided into three main units of engineering geology (Karamniayi and Dehghan 2019) according to the studies (field works, laboratory and field experiments, borehole drilling, hand sumps). 
Fig. 3 features out the longitudinal geological profile of tunnel route. As indicated in Fig. 3, the dominant soil in the tunnel route is D2-1. Thus, the soil properties in this area are used for the numerical analysis. According to studies, the underground water is relatively deep, and the Zarbalizadeh underpass is located above it.

\section{Table 1}

Fig. 3

\subsection{Excavation method}

Tunnel design and construction requires the use of appropriate techniques and technologies during all phases of a tunnel project. One of the popular methods for tunnel design and construction in urban areas is NATM (Taromi et al. 2017). In this method, generally, the total cross-section area is divided into smaller parts and the construction activities are followed in different aspects with certain steps and distances in order to damage lower excavating space (He et al. 2019). Experts have presented different patterns for excavating using such methods (Karamniayi and Dehghan 2019). The most common pattern of this type is a side drift method (which is known as goat horns in Iran). Zarbalizadeh tunnel has been excavated by side drift method. Fig. 4 shows the tunnel excavating sequence which has been applied to this tunnel. The excavation starts from gallery No.1 and when the excavation length reaches $4 \mathrm{~m}$, the excavation of gallery 2 begins. When the excavation of gallery 1 and 2 reached $8 \mathrm{~m}$ and $4 \mathrm{~m}$, respectively, the excavation of gallery 3 is initiated. The process of excavation of galleries in the eastern and western portals is simultaneously done so that the upper part of the tunnel (including galleries 1 to 3 ) is completely excavated. The excavation of the lower part of the tunnel (which includes galleries 4 to 6 ) is the same as the excavation trend of the upper part. The excavation of all galleries almost finishes in the middle of the tunnel axis.

Fig. 4

\subsection{Support systems}

The support systems used in this tunnel include pre-support systems and main support systems.

\subsubsection{Pre-support system}

A. Progressive beam: The very small cross-section tunnels (micro tunnel) with a height of $140 \mathrm{~cm}$, width of 75 $\mathrm{cm}$ and length $44 \mathrm{~m}$ are performed before tunnel excavation and They are reinforced by concrete and steel reinforcement cage (Fig. 5a).

B. Fore-poling: Manisman pipes with external diameter of $76 \mathrm{~mm}$, thickness of $4 \mathrm{~mm}$, length $8 \mathrm{~m}$ and the angle of $8^{\circ}$ to the tunnel axis with the transverse intervals of $0.5 \mathrm{~cm}$ and the longitudinal interval of $2 \mathrm{~m}$ have been considered. Forepooling is simultaneously performed with the excavation of the upper galleries (galleries 1 to 3 ) with a transverse distance of $0.5 \mathrm{~m}$ and a longitudinal distance of $2 \mathrm{~m}$ from each other, and its angle to the tunnel axis is 8 degrees. (Fig. 5b).

Fig. 5c shows the location of the progressive beams and fore-poling pre-support system in the tunnel cross-section. 
Fig. 5 a Dimension of progressive beam b Fore-poling properties $\mathbf{c}$ Location of the pre-support systems

\subsubsection{Main support system}

A. Composite support system: this system comprises a permanent and temporary support. The permanent support includes lattice girders 3 bars (steel type AIII $(\varphi=20,28)$ ), shotcrete and two layers of wire mesh. The longitudinal distance of the main supports from each other is $1 \mathrm{~m}$. The temporary support includes lattice girders 3 bars (steel type AIII $(\varphi=18,25))$, shotcrete and two layers of wire mesh. Longitudinal distance of temporary supports from each other is $1 \mathrm{~m}$ (Fig. 6a).

B. Lining: The concrete with compressive strength equal $300 \mathrm{~kg} / \mathrm{cm}$ and rebar AIII with yield Strength equal $4000 \mathrm{~kg} / \mathrm{cm}^{2}$ is considered for designing the lining structure. Moreover, the thickness of lining section is 50 $\mathrm{cm}$ in the final designing (Fig. 6b).

Fig. 6

\section{Numerical modeling}

For three-dimensional modeling of Zarbalizadeh tunnel, a model with appropriate grouping (according to the arrangement and sequence of tunnel excavation (Fig. 4)) and 407968 zones were created (Fig. 7a and Fig. 8a). The dimensions of the model $90 \times 44 \times 35$ were selected to ensure that there are no obvious boundary effects. (Fig. $7 \mathrm{~b}$ ). A uniform load of 93.5Kpa (Karamniayi and Dehghan 2019) is applied along the direction of the railways on the model (the load caused by the train passing). The in-situ stresses are considered as gravity and the ratio of the horizontal stress of the vertical stress ( $\left.\mathrm{K}_{0}\right)$ is based on Jaky's formula (Jaky 1948). The failure criterion assumed in these analyses was the Mohr-Coulomb criterion. Pre-support systems of progressive beam and fore-poling are equalized by the pile element. The composite support system (wire mesh, shotcrete and lattice girder) is equalized like equivalent section and by the shell element. Lastly, the final lining and the impact range of fore-poling grout (soilcrete) are equalized by volumetric elements (Fig. 8b).

Fig. 7

Fig. 8

The steps of modeling are the following: 1) Creating gravitational stresses and assigning constant soil properties to the model (Table 2), applying surface load caused by passing trains and then running the model until it reaches the equilibrium 2) installing pre-support systems (progressive beam, fore-poling and soilcrete zones) and applying their properties (Tables 2 and 3), excavation side wall drifts according to the pattern of Figure 4 from both sides of model (excavation steps are $1 \mathrm{~m}$ ) and running the model until it reaches the equilibrium 3) excavating Side wall drifts according to pattern of Figure 4 from both sides of model, Installing composite support systems (permanent and temporary) and applying their properties (Table 4) one meter backward from the working face, the fore-poling is reinstalled when the distance between the working face of each drifts 1 to 3 from each portal is equal to the even 
number and running the model again until it reaches the equilibrium 4) repeating step 3 until a complete excavation by the model. Afterwards, the temporary support system is removed, and the final lining and its properties are installed and applied respectively (Table 2). The excavation of the tunnel is simulated by using a stress reduction method to account for the delayed installation of the tunnel lining and the load sharing between ground and lining (Möller 2006).

Table 2.

Table 3

\section{Table 4}

\subsection{Verification of the numerical model}

Prior to the main analysis, the numerical model was developed and verified based on the data measured from the Zarbalizadeh underpass project. In this project, a monitoring system was designed and implemented to detect the ground behavior and the support system behavior. Surface settlement was monitored by settlement point using leveling instruments. Fig. 9 shows the schematic monitoring section of the Zarbalizadeh tunnel route. Moreover, Fig. 10 shows the results of the measured data at a distance of $16 \mathrm{~m}$ from the eastern portal. Also Fig. 11 shows the contour of the vertical displacement in the verified Three-dimensional FDM. According to Figures $12 a$ and $12 b$, the $S_{\max }$ of numerical analysis and field measuring is $28.6 \mathrm{~mm}$ and $30.9 \mathrm{~mm}$ respectively. The result indicates a good compliance between the numerical results and the field measurement data (a difference of approximately $5 \%$ was identified). Therefore, it could be concluded that the numerical model is verified and simulations could be carried out on the developed model.

Fig. 9

Fig. 10

Fig. 11

Fig. 12.

The longitudinal profile of the $S_{\max }$ is also obtained by extracting the maximum $Z_{-}$displacement values along the $\mathrm{Y}$ axis from the numerical model. The symmetry in the middle of the curve is due to the tunnel simultaneous excavation from eastern \& western portal and completing the excavation of all side drifts in the middle part of the tunnel.

\subsection{Random finite difference analysis}

To generate a random field by the spatial variability of Young's modulus, the log-normal distribution (see Section 32) is adopted to characterize the variability of the Young's modulus with its mean $E s=27 \mathrm{MPa}$, and $\mathrm{COV}_{\mathrm{E}}=0.2$ in this research. Then, the coordinate center of all FDM zones is extracted to allocate the created random field in the numerical model. Consequently, the specifications of the center of all the zones of the model are extracted to allocate the created random field to the numerical model. Some hypotheses are considered to facilitate the process of creating a random field: 1) regarding the long calculation time, the vertical SOF is assumed to be one meter $(\theta \mathrm{z})$. Since the value of the horizontal SOF hasn't been considered, some typical values of horizontal SOF have been assumed as presumption; 2) During the analysis process, it is assumed that both horizontal SOFs ( $\left.\theta_{\mathrm{X}}, \theta_{\mathrm{Y}}\right)$ are equal (Kawa and Puła 2019); 3) All soil properties are considered constant and only the soil Young's modulus has a log-normal 
distribution. As the value of the SOF and the type of statistical distribution of the Young's modules are determined, it is necessary to change these two parameters within the permissible range of their domain. For this purpose, the MCS is used because it has the advantage of robustness and conceptual simplicity. It should be pointed out that if MCS methods and numerical methods (specially the three-dimensional numerical method) are used and integrated with one another, we will have a time-consuming and complex analysis. Seven different values are examined for horizontal SOFs $(2,5,10,20,40,60,100 \mathrm{~m})$ and the elastic module is changed as much as 1000 times by MCS for each horizontal SOF. In other words, 7000 simulations are performed and 7000 numerical models are executed. Due to the time duration of 7 to $10 \mathrm{~min}$, it took two months to perform the numerical model for each simulation by laptop with specifications including 16 Giga byte memory, a CPU Intel Core i7 processor and the frequency of $3.8 \mathrm{GHz}$ in order to conduct this high volume of calculation.

\section{The Effects of random field}

As mentioned in the previous section, $\mathrm{N}=1000$ of MCS are performed for each SOF. Based on the data collected in each MCS, mean and the COV of $S_{\max }$ were calculated along the tunnel axis. The variation of both the mean value and the COV of $S_{\max }$ consistently grows with increasing SOF but these soon stabilize for higher values of SOF (Figs. $13 \mathrm{a}$ and 13b). On the other hand, the change in COV is quite significant. Its value increases from 0.01 to 0.34 . Thus, it indicates that in case the spatial variability is ignored, the risk of the permissible excessive settlement will not be taken into account in the designing calculations. Fig. $13 \mathrm{~b}$ also shows the COV of $\mathrm{S}_{\max }$ will tend to a straight line when SOF becomes more than $2.8 \mathrm{D}$ ( $\mathrm{W}$ is the width of the tunnel (the reason is that, the induced stresses caused by tunneling is rapidly reduced in the main effective area of the tunnel (Gong et al. 2014).

\section{Fig. 13}

Fig. 14a illustrates the value of the vertical displacement along the tunnel axis with the horizontal SOF of $100 \mathrm{~m}$ for 1000 MCS. As observed in Fig. 14b, the value of the surface settlement varies in the range of $6 \mathrm{~mm}$ to $83 \mathrm{~mm}$.

\section{Fig. 14}

Another effect of the random field is the asymmetry of the surface settlement both in the cross- section and in the longitudinal profile of the tunnel. When a region with low strength takes place in the influenced zone (Fig. 15a), the surface settlement becomes asymmetric around the tunnel axis (Fig. 15b). In other words, the situation of the $S_{\max }$ is deviated from the tunnel axis (Figure 15c and 15d). Obviously, outside the range of influence due to tunnel excavation, the existence of a low strength region will not affect the distribution pattern of the surface deformation.

Fig. 15 


\section{Evaluation of the Probability of Failure}

For tunneling in urban areas, the allowable limit $\left(\mathrm{S}_{\mathrm{lim}}\right)$ of $\mathrm{S}_{\max }$ as key parameter should be specified. The selection of the $S_{\text {lim }}$ is an important problem because it has a significant effect on the stability of the tunnel and detrimental influence on adjacent structures. Hence it is necessary to investigate the probability of failure for $S_{\max }$ exceeding the $\mathrm{S}_{\mathrm{lim}}$. It should be noted that, for the sake of clarity, the term "probability of failure" is defined as $\left(\mathrm{P}_{\mathrm{f}}\right)$. In this analysis, the probability of failure was defined as (Cheng et al. 2019a; Cheng et al. 2019b)

$$
P_{f}=\frac{N_{f}}{N} \times 100 \%
$$

Where $\mathrm{N}=$ number of realizations; $\mathrm{N}_{f}=$ number of $\mathrm{S}_{\max }$ exceeding the $\mathrm{S}_{\text {lim }}$ in $\mathrm{N}$ realizations (in this study, the value of $\mathrm{N}$ was set to 1000). As shown in Fig. 16, the $S_{\text {lim }}$ of $S_{\max }$ increases for all levels of COV of soil Young's modulus. Likewise, increases in COV leads to decreases in the probability of failure for the $S_{\text {lim }}$ smaller than the FDM verification results. However, the probability of failure increases as COV increases for each $\mathrm{S}_{\text {lim }}$ greater than the FDM verification results. Therefore, the negligence of the variability of soil Young's modulus in the probabilistic analysis of the surface settlement can lead to an underestimation of the probability of failure.

\section{Fig. 16}

\section{The Evaluation of the reliability index}

The reliability index ( $\beta$ ) of not exceeding the surface settlement can be computed as (Griffiths and Fenton 2008)

$$
\beta=\Phi^{-1}\left(1-P_{f}\right)
$$

Where $\Phi$ is the cumulative distribution function of one dimensional standard normal distribution and $\mathrm{P}_{\mathrm{f}}$ is the probability of exceedance. If $S_{\lim }=40 \mathrm{~mm}$, the obtained reliability index for all COV is in accordance with Table 5 . Therefore, the lowest value of reliability index is related to the larger mean value and the highest $\mathrm{P}_{\mathrm{f}}$ value.

\section{Table 5}

Conclusively, as the COV is increased, the reliability index will be decreased.

\section{Conclusions}

The present paper has scrutinized the effect of spatial variability of soil Young's module on $\mathrm{S}_{\max }$ caused by tunneling using the NATM. The research findings are summarized as below:

For statistical analysis of the random field of NATM tunnels, it is better to use a three-dimensional modeling rather than a two-dimensional one. As shown in Section 5, the problem of asymmetry of the surface settlement is evident 
both in the cross-section and in the longitudinal profile of the tunnel. Therefore, the use of two-dimensional methods cannot provide a comprehensive analysis of the surface settlement conditions.

The mean values of $S_{\max }$ in the random analysis are approximately equal to the $S_{\max }$ obtained from the numerical model in the deterministic mode (the correlation value of parameter $\mathrm{E}$ is increased and gets closer to the deterministic condition through enhancing the SOF). Nevertheless, the $\mathrm{COV}$ of $\mathrm{S}_{\max }$ is significantly increased. Hence, ignoring the spatial variability can lead to the dangerous underestimation of the risk of excessive settlement.

Regarding to the relationship between the probability of failure and the permitted surface settlement, there is the fact that ignoring the variability of the soil's Young's modulus causes to ignore the failure probability up to $50 \%$. Indeed, it remarkably affects the design of the method implementation and the choice of the type of support systems.

\section{References}

Bagińska I, Kawa M, Janecki W (2016) Estimation of spatial variability of lignite mine dumping ground soil properties using CPTu results Studia Geotechnica et Mechanica 38:3-13

Bagińska I, Kawa M, Janecki W (2018) Estimation of spatial variability properties of mine waste dump using CPTu results - case study Cone penetration testing:109-115

Cheng H, Chen J, Chen R, Chen G (2019a) Comparison of modeling soil parameters using random variables and random fields in reliability analysis of tunnel face International Journal of Geomechanics 19:04018184

Cheng H, Chen J, Li J (2019b) Probabilistic Analysis of Ground Movements Caused by Tunneling in a Spatially Variable Soil International Journal of Geomechanics 19:04019125

Cherubini C Data and considerations on the variability of geotechnical properties of soils. In: Proceedings of the Conference on Advances in Safety and Reliability, ESREL, 1997. pp 1583-1591

Dasaka S, Zhang L (2012) Spatial variability of in situ weathered soil Géotechnique 62:375-384

Fenton GA, Griffiths D (2002) Probabilistic foundation settlement on spatially random soil Journal of Geotechnical and Geoenvironmental Engineering 128:381-390

Fenton GA, Griffiths D (2003) Bearing-capacity prediction of spatially random c $\varphi$ soils Canadian geotechnical journal 40:54-65

Fenton GA, Griffiths D (2005) Three-dimensional probabilistic foundation settlement Journal of Geotechnical and Geoenvironmental Engineering 131:232-239

Gong W, Luo Z, Juang CH, Huang H, Zhang J, Wang L (2014) Optimization of site exploration program for improved prediction of tunneling-induced ground settlement in clays Computers and Geotechnics 56:69-79

Griffiths D, Fenton GA (2001) Bearing capacity of spatially random soil: the undrained clay Prandtl problem revisited Geotechnique 51:351-359

Griffiths D, Fenton GA, Manoharan N (2006) Undrained bearing capacity of two-strip footings on spatially random soil International Journal of Geomechanics 6:421-427

Griffiths DV, Fenton G (2008) Risk assessment in geotechnical engineering John wiley\&Sons, Inc:381-400 
Gui M-W, Chen S-L (2013) Estimation of transverse ground surface settlement induced by DOT shield tunneling Tunnelling and Underground Space Technology 33:119-130

He B-G, Zhang X-W, Li H-P (2019) Ground load on tunnels built using new Austrian tunneling method: study of a tunnel passing through highly weathered sandstone Bulletin of Engineering Geology and the Environment 78:6221-6234

Huang J, Lyamin A, Griffiths D, Krabbenhoft K, Sloan S (2013) Quantitative risk assessment of landslide by limit analysis and random fields Computers and Geotechnics 53:60-67

Jaksa MB, Brooker PI, Kaggwa WS (1997) Inaccuracies associated with estimating random measurement errors Journal of Geotechnical and Geoenvironmental Engineering 123:393401

Jaky J (1948) Pressure in silos Proc 2nd ICSM, 1948

Karamniayi FM, Dehghan A (2019) The Effect of Pre-Support System (Forepoling) on the Control of Ground Surface Subsidence caused by SEM/NATM in Shallow Urban Road Tunnels under Railway Traffic Loading

Kawa M, Puła W (2019) 3D bearing capacity probabilistic analyses of footings on spatially variable c- $\varphi$ soil Acta Geotechnica doi:10.1007/s11440-019-00853-3

Li D-Q, Jiang S-H, Cao Z-J, Zhou W, Zhou C-B, Zhang L-M (2015) A multiple response-surface method for slope reliability analysis considering spatial variability of soil properties Engineering Geology 187:60-72

Marinos V, Goricki A, Malandrakis E (2019) Determining the principles of tunnel support based on the engineering geological behaviour types: example of a tunnel in tectonically disturbed heterogeneous rock in Serbia Bulletin of Engineering Geology and the Environment 78:2887-2902

Miro S, König M, Hartmann D, Schanz T (2015) A probabilistic analysis of subsoil parameters uncertainty impacts on tunnel-induced ground movements with a back-analysis study Computers and Geotechnics 68:38-53

Möller SC (2006) Tunnel induced settlements and structural forces in linings. Univ. Stuttgart, Inst. f. Geotechnik Stuttgart, Germany,

Mollon G, Dias D, Soubra A-H (2013) Probabilistic analyses of tunneling-induced ground movements Acta Geotechnica 8:181-199

Moosavi E, Shirinabadi R, Rahimi E, Gholinejad M (2018) Numerical Modeling of Ground Movement due to Twin Tunnel Structure of Esfahan Subway, Iran Journal of Mining Science 53:663-675

Nadim F (2007) Tools and strategies for dealing with uncertainty in geotechnics. In: Probabilistic methods in geotechnical engineering. Springer, pp 71-95

Phoon K-K, Kulhawy FH (1999) Characterization of geotechnical variability Canadian geotechnical journal 36:612-624

Sivakumar Babu G, Mukesh M (2004) Effect of soil variability on reliability of soil slopes Geotechnique 54:335-337

Taromi M, Eftekhari A, Hamidi JK, Aalianvari A (2017) A discrepancy between observed and predicted NATM tunnel behaviors and updating: a case study of the Sabzkuh tunnel Bulletin of Engineering Geology and the Environment 76:713-729

Uzielli M, Vannucchi G, Phoon K (2005) Random field characterisation of stress-nomalised cone penetration testing parameters Geotechnique 55:3-20

Vanmarcke E (2010) Random fields: analysis and synthesis. World Scientific, 
Vanmarcke EH (1977) Probabilistic modeling of soil profiles Journal of the geotechnical engineering division 103:1227-1246

Wei L, Tumay MT, Abu-Farsakh MY (2005) Field testing of inclined cone penetration Geotechnical Testing Journal 28:31-41

Zhou X-P, Zhu B-Z, Juang C-H, Wong LNY (2019) A stability analysis of a layered-soil slope based on random field Bulletin of Engineering Geology and the Environment 78:26112625 
Table 1 Geotechnical properties of soil layers.

\begin{tabular}{|c|c|c|c|c|c|c|c|c|c|c|c|c|}
\hline \multirow[t]{2}{*}{ Type } & \multicolumn{2}{|c|}{$\begin{array}{c}\text { Cohesion } \\
\text { C (kg/cm2) }\end{array}$} & \multicolumn{2}{|c|}{$\begin{array}{c}\text { Friction angle } \\
\qquad \text { (deg) }\end{array}$} & \multirow[t]{2}{*}{$\begin{array}{c}\text { Elastic modulus } \\
\text { E (kg/cm2) }\end{array}$} & \multirow[t]{2}{*}{$\begin{array}{c}\text { Poisson's } \\
\text { Ratio }\end{array}$} & \multicolumn{3}{|c|}{$\begin{array}{c}\text { Unit weight } \\
\gamma(\mathrm{g} / \mathrm{cm} 3)\end{array}$} & \multicolumn{3}{|c|}{$\begin{array}{c}\text { Consolidation } \\
\text { (kg/cm2) }\end{array}$} \\
\hline & $\mathrm{C}^{\prime}$ & $\mathrm{Ccu}$ & $' \varphi$ & $\operatorname{cu} \varphi$ & & & Dry & Wet & Sat & $\mathrm{Cc}$ & Cs & $\mathbf{P c}$ \\
\hline D2-2 & $0.32 \pm 0.1$ & $0.42 \pm 0.1$ & $27 \pm 2$ & $20 \pm 2$ & $260 \pm 50$ & 0.30 & $1.65 \pm 0.1$ & $1.80+0.1$ & $1.85+0.1$ & $0.2-0.3$ & $0.03-0.04$ & $3-3.5$ \\
\hline D2-1 & $0.30 \pm 0.1$ & $0.36 \pm 0.1$ & $28 \pm 2$ & $21 \pm 2$ & $280 \pm 50$ & 0.30 & $1.60 \pm 0.1$ & $1.80+0.1$ & $1.85+0.1$ & $0.1-0.2$ & $0.03-0.04$ & $2-2.5$ \\
\hline D1-2 & $0.31 \pm 0.1$ & $0.30 \pm 0.1$ & $30 \pm 2$ & $23 \pm 2$ & $300 \pm 50$ & 0.32 & $1.65 \pm 0.1$ & $1.80+0.1$ & $1.85+0.1$ & $0.2-0.3$ & $0.02-0.03$ & $2.8-3.2$ \\
\hline $\mathrm{C} 1$ & $0.20 \pm 0.1$ & $0.25 \pm 0.1$ & $34 \pm 2$ & $25 \pm 2$ & $520 \pm 50$ & 0.31 & $1.70 \pm 0.1$ & $1.85 \pm 0.1$ & $1.90 \pm 0.1$ & $0.15-0.25$ & $0.025-0.035$ & $2.5-3.5$ \\
\hline B & $0.12 \pm 0.1$ & $0.20 \pm 0.1$ & $35 \pm 2$ & $30 \pm 2$ & $600 \pm 50$ & 0.31 & $1.80 \pm 0.1$ & $1.90 \pm 0.1$ & $1.95 \pm 0.1$ & - & - & - \\
\hline
\end{tabular}

Table 2 Volumetric elements properties used in modelling.

\begin{tabular}{|c|c|c|c|c|c|c|}
\hline $\begin{array}{l}\text { volumetric } \\
\text { element type }\end{array}$ & $\begin{array}{c}\text { Friction angel } \\
\varphi\left({ }^{0}\right)\end{array}$ & $\begin{array}{c}\text { Cohesion } \\
\text { C (Kpa) }\end{array}$ & $\begin{array}{c}\text { Unit } \\
\text { weight } \\
\left(\mathrm{Kg}^{2} \mathbf{m}^{3}\right)\end{array}$ & $\begin{array}{c}\text { Poisson's } \\
\text { ratio } \\
v \\
\end{array}$ & $\begin{array}{c}\text { Young's } \\
\text { modulus } \\
\text { E(GPa) }\end{array}$ & $\begin{array}{c}\text { Thickness } \\
\text { d (cm) }\end{array}$ \\
\hline Soil & 28 & 29.5 & 1600 & 0.3 & 0.275 & - \\
\hline Soilcrete & 35 & 4200 & 2300 & 0.25 & 2.6 & - \\
\hline Lining & - & - & 2400 & 0.2 & 20 & 50 \\
\hline
\end{tabular}

Table 3 Pre-support systems properties used in modelling.

\begin{tabular}{|c|c|c|c|c|c|c|c|}
\hline $\begin{array}{l}\text { Pre-support } \\
\text { system type }\end{array}$ & $\begin{array}{c}\text { polar } \\
\text { moment of } \\
\text { inertia } \\
\mathbf{J}\left(\mathbf{m}^{\mathbf{4}}\right)\end{array}$ & $\operatorname{Iz}\left(\mathbf{m}^{4}\right)$ & Iy $\left(\mathbf{m}^{4}\right)$ & $\begin{array}{c}\text { exposed } \\
\text { perimeter } \\
\mathbf{P}(\mathbf{m})\end{array}$ & $\begin{array}{c}\text { cross- } \\
\text { sectional area } \\
\mathbf{A}\left(\mathbf{m}^{2}\right)\end{array}$ & $\begin{array}{c}\text { Poisson's } \\
\text { ratio } \\
v\end{array}$ & $\begin{array}{c}\text { Young's } \\
\text { modulus } \\
\text { E(GPa) }\end{array}$ \\
\hline Progressive beam & 0.0421 & 0.0331 & 0.1052 & 3.532 & 0.854 & 0.3 & 30 \\
\hline Fore-poling & 0.00 & 0.0190 & 0.0190 & 0.2388 & 0.0045 & 0.3 & 200 \\
\hline
\end{tabular}

Table 4 Composite support systems properties used in modelling.

\begin{tabular}{cccc}
\hline $\begin{array}{c}\text { Composite support } \\
\text { system type }\end{array}$ & $\begin{array}{c}\text { Thickness } \\
\text { d (cm) }\end{array}$ & $\begin{array}{c}\text { Poisson's ratio } \\
\text { v }\end{array}$ & $\begin{array}{c}\text { Young's modulus } \\
\text { E(GPa) }\end{array}$ \\
\hline Permanent support & 30 & 0.3 & 15 \\
Temporary support & 25 & 0.25 & 10 \\
\hline
\end{tabular}

Table 5 The reliability index for different values of $P_{f}$ when $S_{\text {lim }}=40 \mathrm{~mm}$

\begin{tabular}{cccc}
\hline Mean $(\mathrm{mm})$ & $\mathrm{SD}(\mathrm{mm})$ & $\mathrm{P}_{\mathrm{f}}(\%)$ & $\beta$ \\
\hline 28.58 & 0.011 & 0.1 & 3.09 \\
29.31 & 0.145 & 9.4 & 1.31 \\
29.86 & 0.226 & 14.7 & 1.04 \\
30.12 & 0.275 & 20.5 & 0.82 \\
30.45 & 0.318 & 19.2 & 0.87 \\
30.81 & 0.337 & 21.7 & 0.78 \\
30.84 & 0.324 & 21.2 & 0.79
\end{tabular}




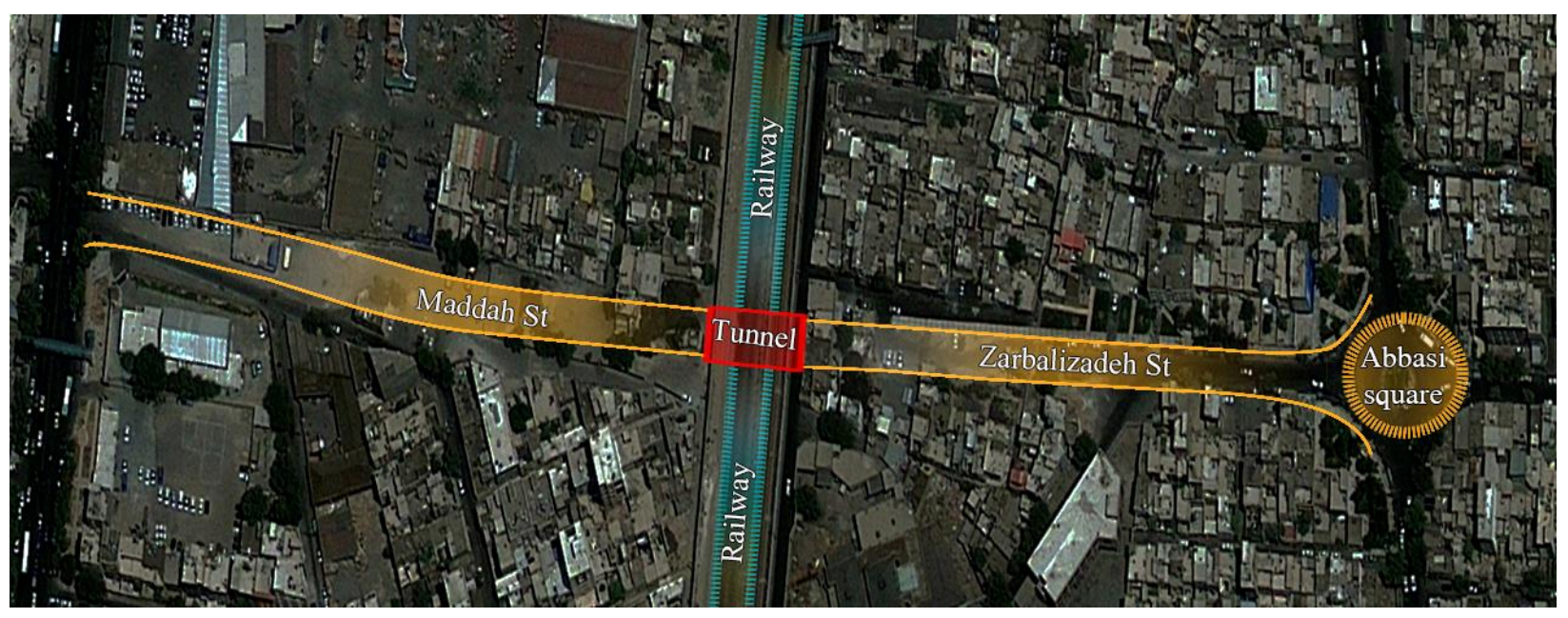

Fig. 1 A plan of Zarbalizadeh tunnel project in urban area in Tehran, Iran.

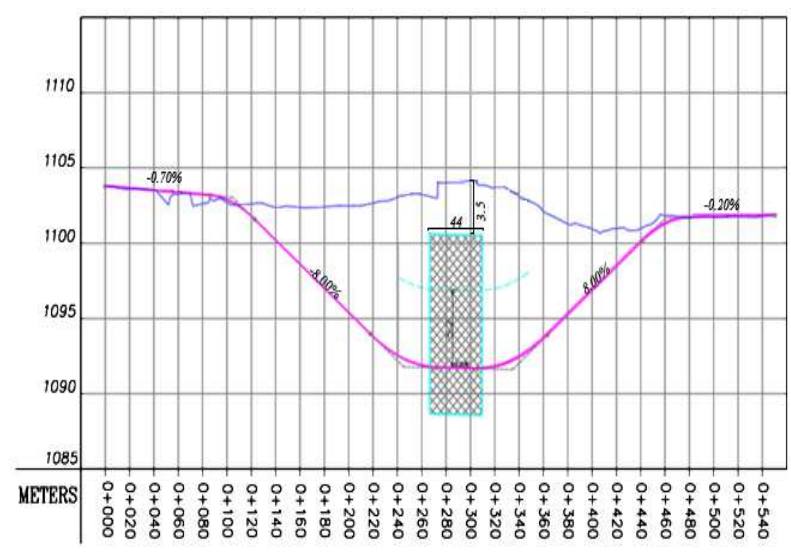

(a)

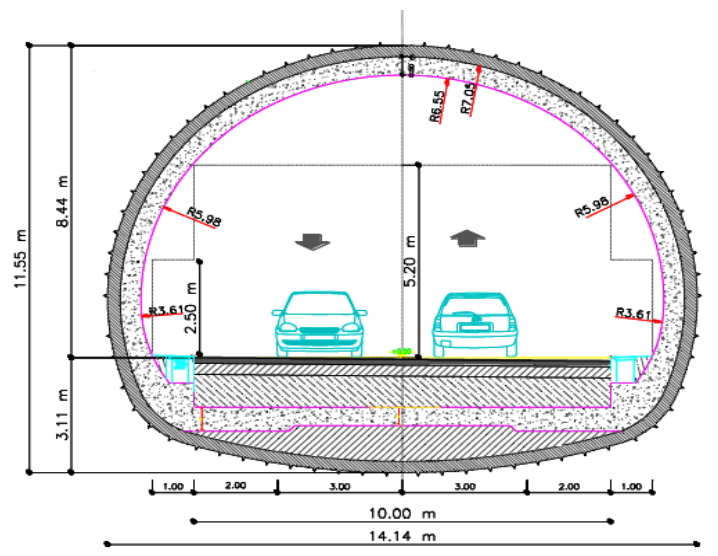

(b)

Fig. 2 a Longitudinal profile b Cross section of Zarbalizadeh tunnel.

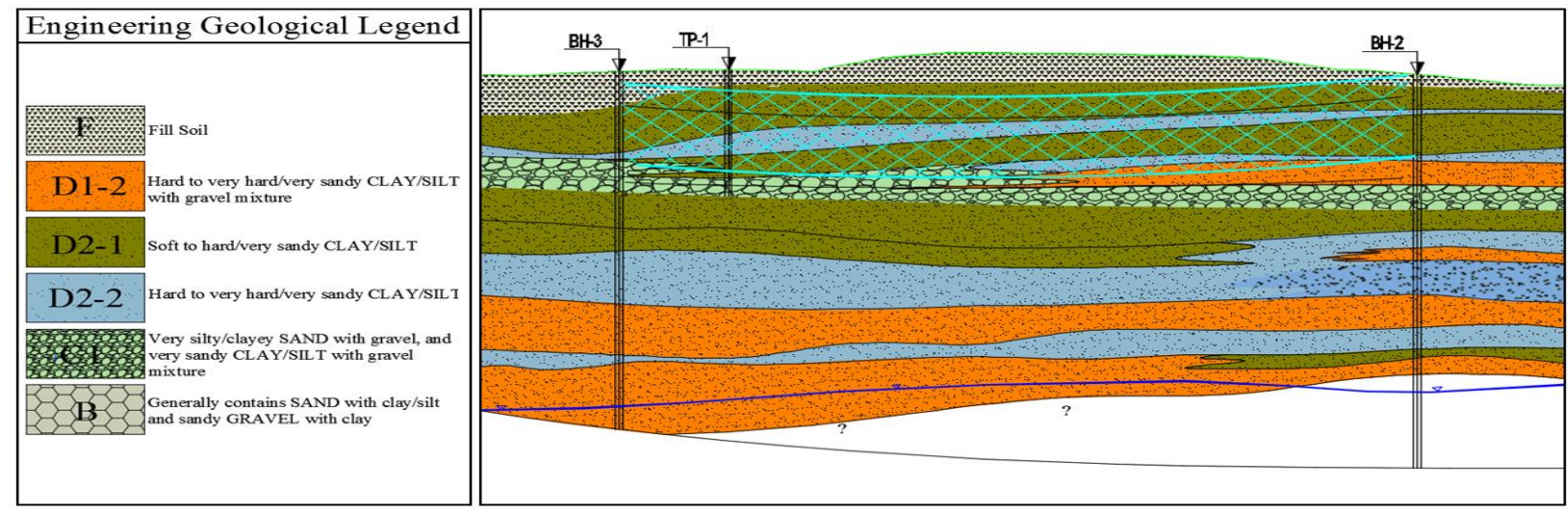

Fig. 3 Longitudinal geological profile of tunnel route 

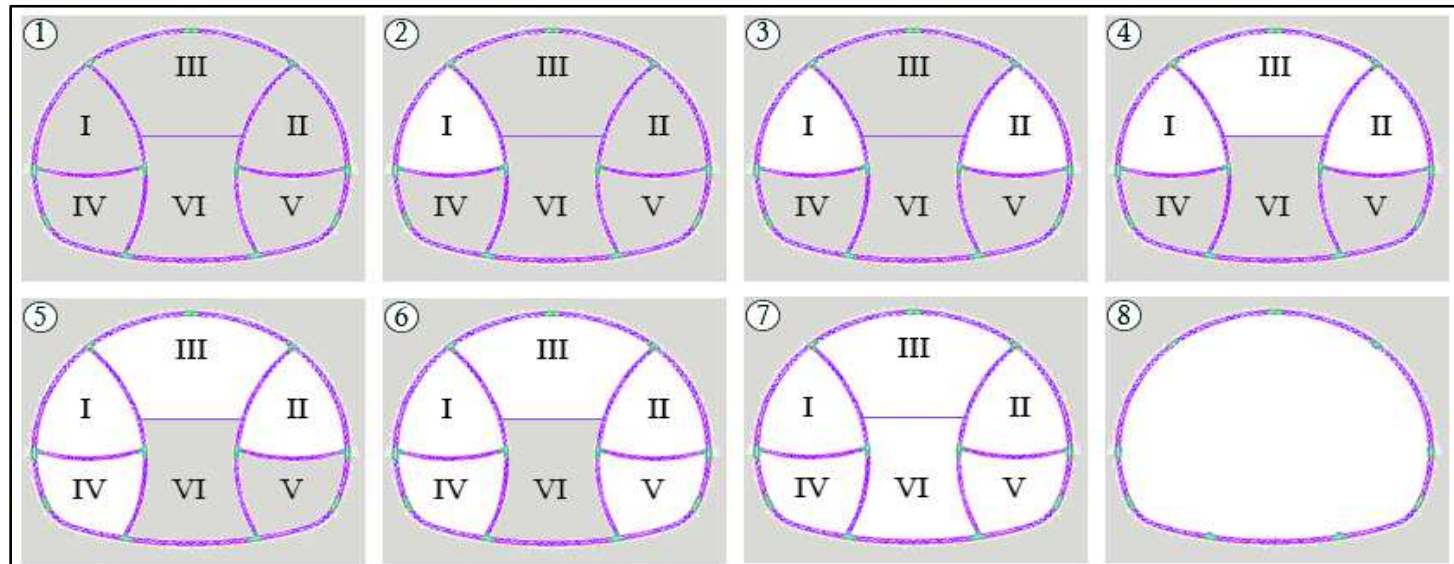

Fig. 4 Arrangement and sequence of Zarbalizadeh tunnel by side drifts method

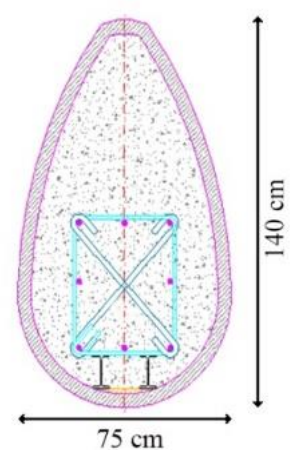

(a)

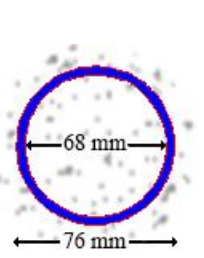

(b)

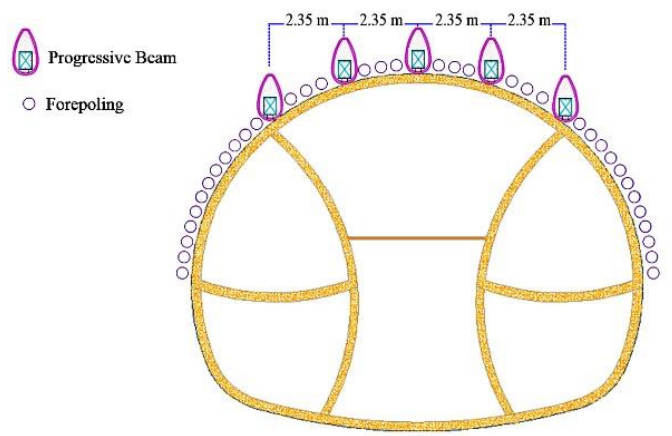

(c)

Fig. 5 a Dimension of progressive beam $\mathbf{b}$ Fore-poling properties $\mathbf{c}$ Location of the pre-support systems

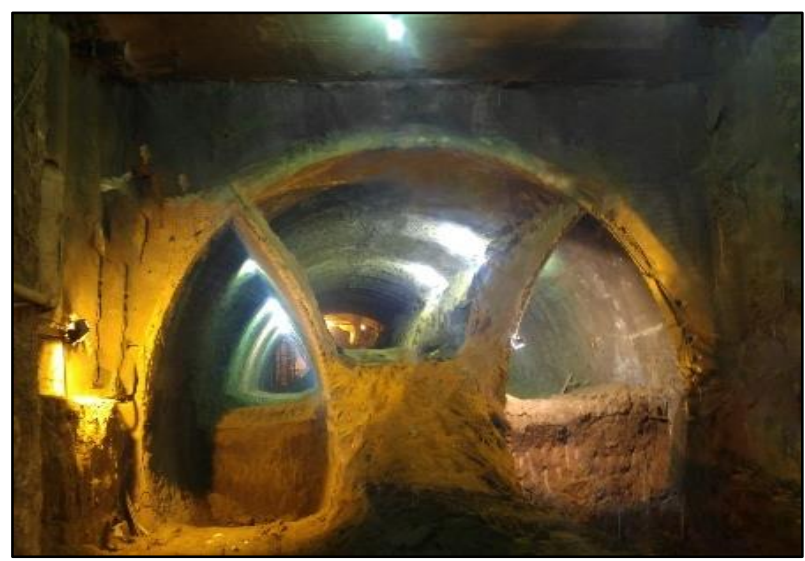

(a)

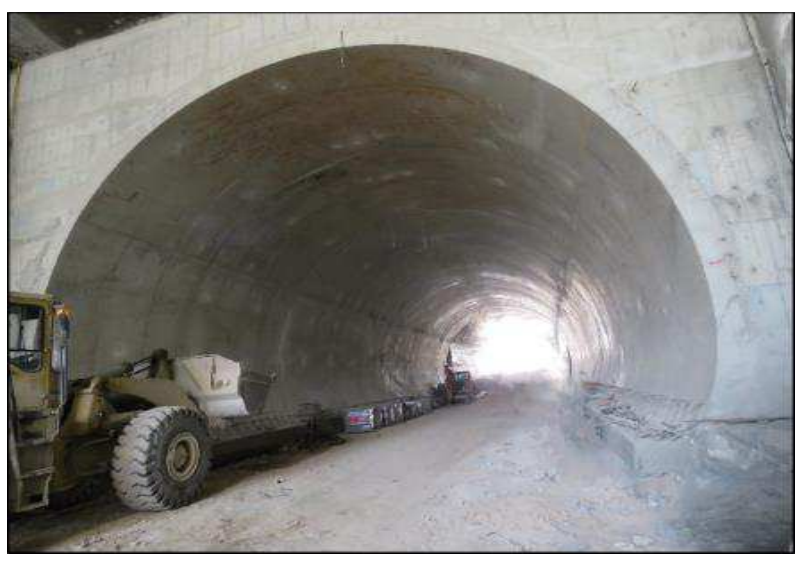

(b)

Fig. 6 a Composite support system b Lining 


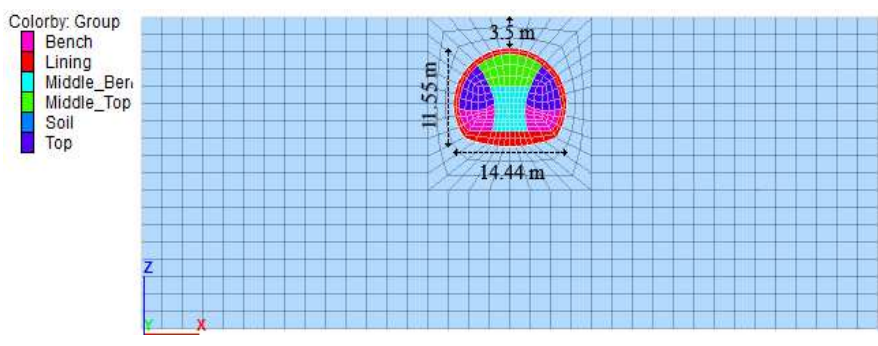

(a)
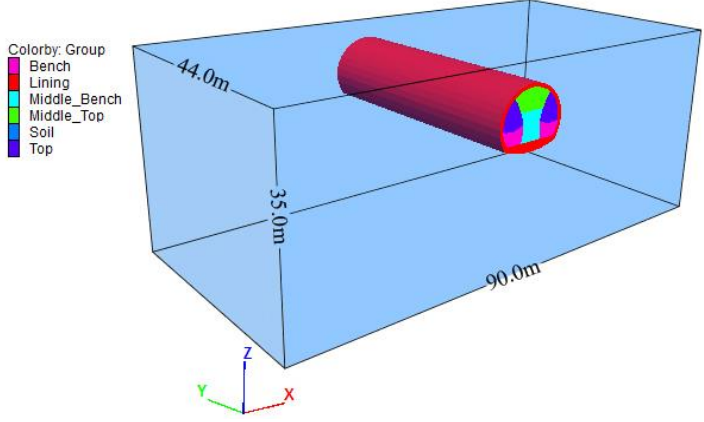

(b)

Fig. 7 Finite difference model a Grouping and dimensions of tunnel in numerical model $\mathbf{b}$ The numerical model boundaries.

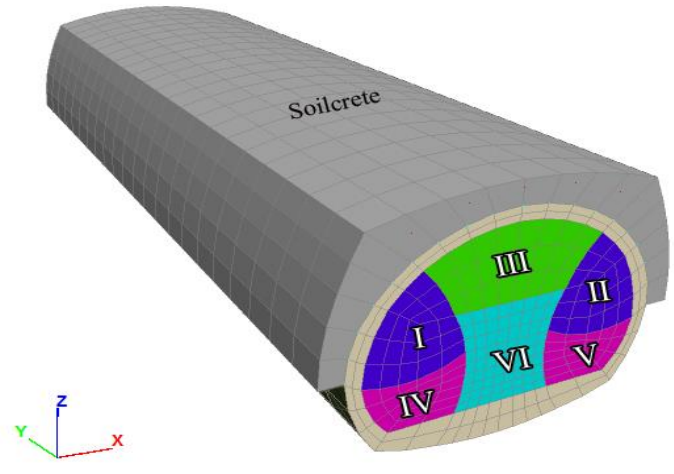

(a)

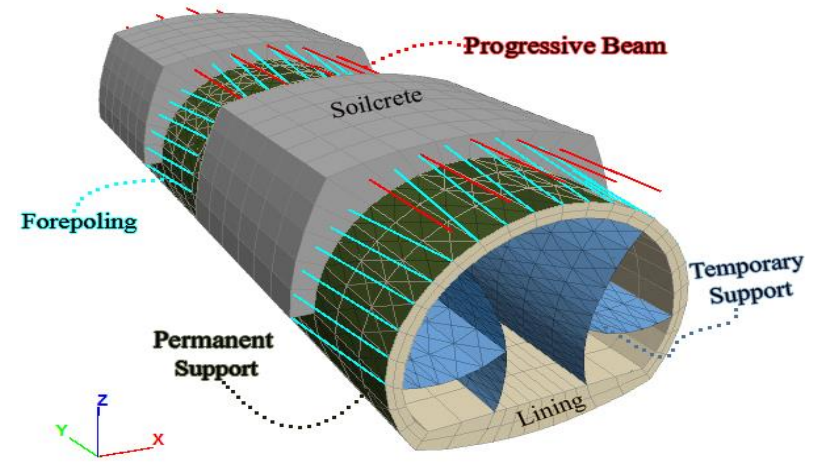

(b)

Fig. 8 a The arrangement and sequence of tunnel excavation in numerical model $\mathbf{b}$ The composite and pre-support systems

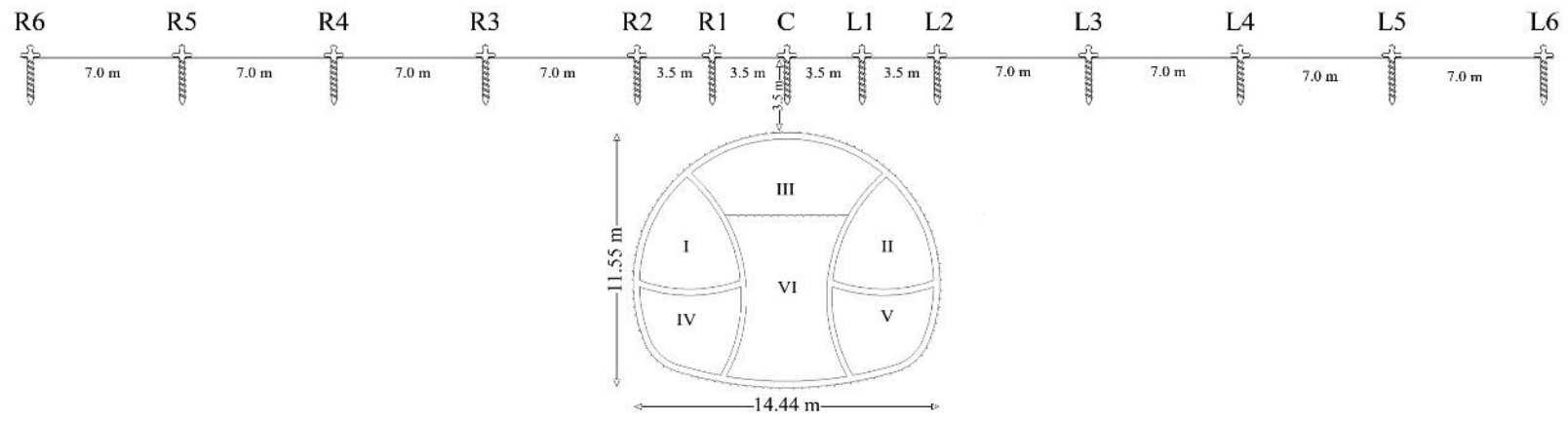

Fig. 9 A typical instrumentation array for tunnel cross section. 


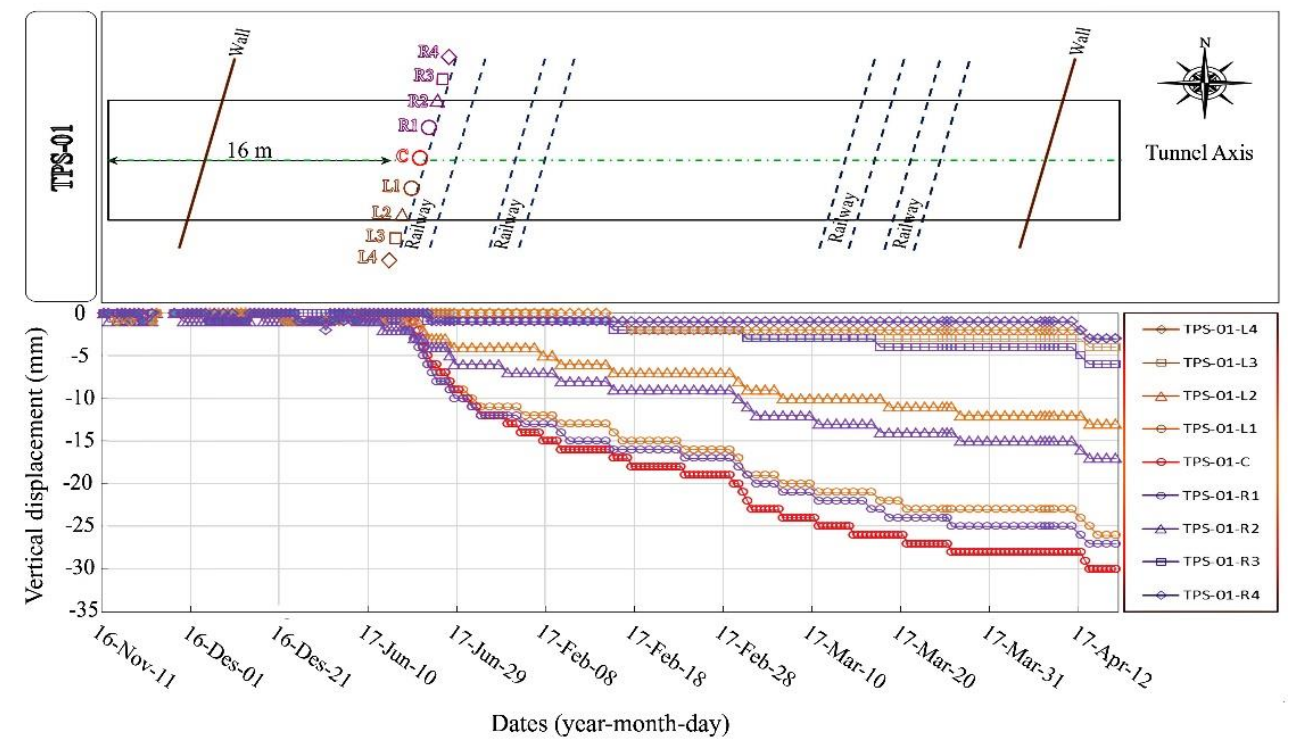

Fig. 10 Surface settlement trough obtained from field measuring in Zarbalizadeh tunnel.

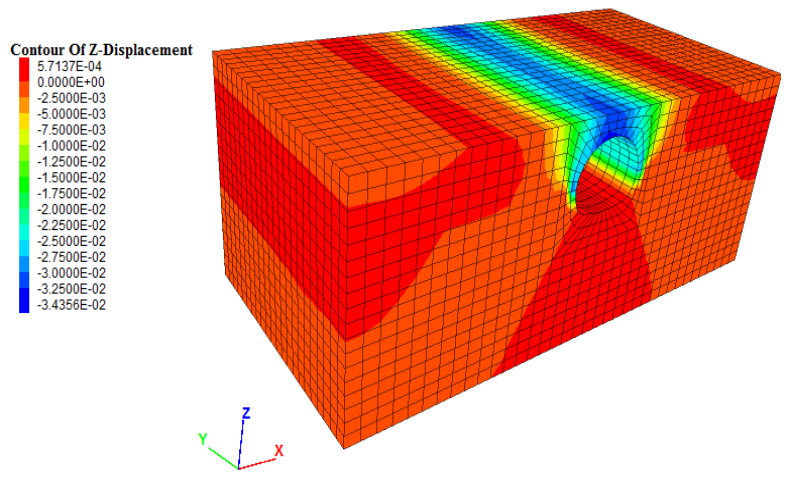

Fig. 11 The verification of numerical model (contour of $Z_{-}$displacement)
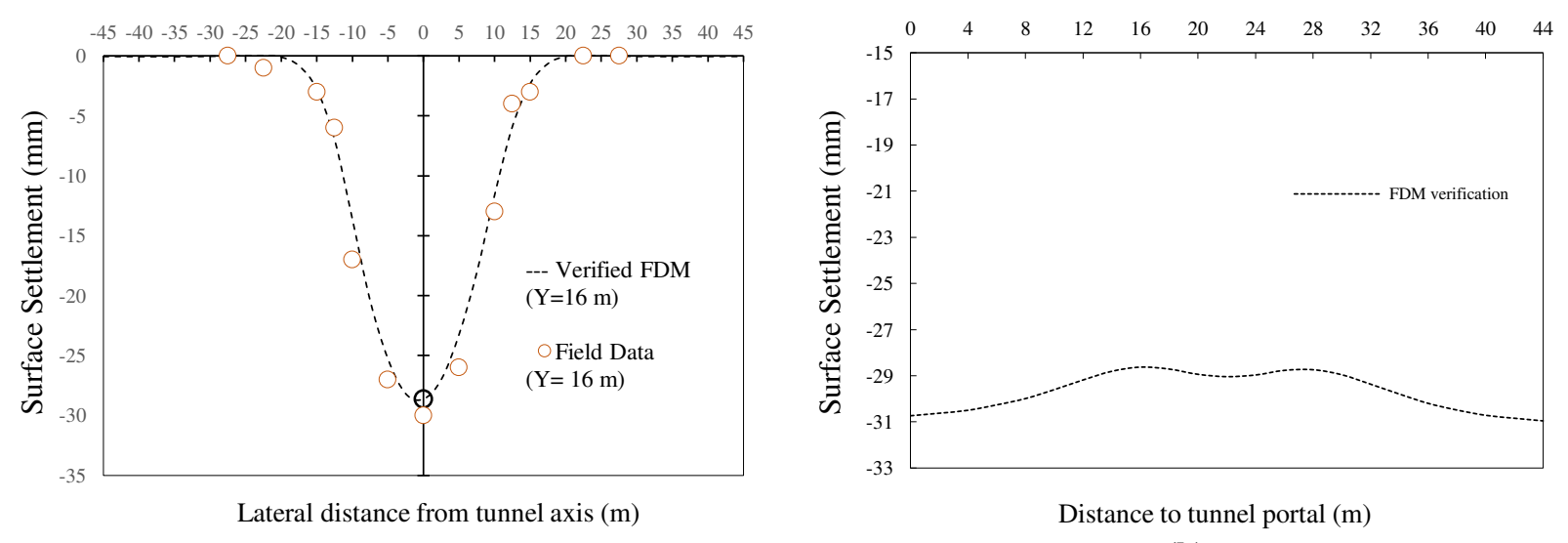

(b)

(a) 
Fig. 12 The verification of numerical model a The verification results of the settlement trough estimated by FDM results and measured data $\mathbf{b}$ The maximum surface settlement along the $\mathrm{Y}$ axis.

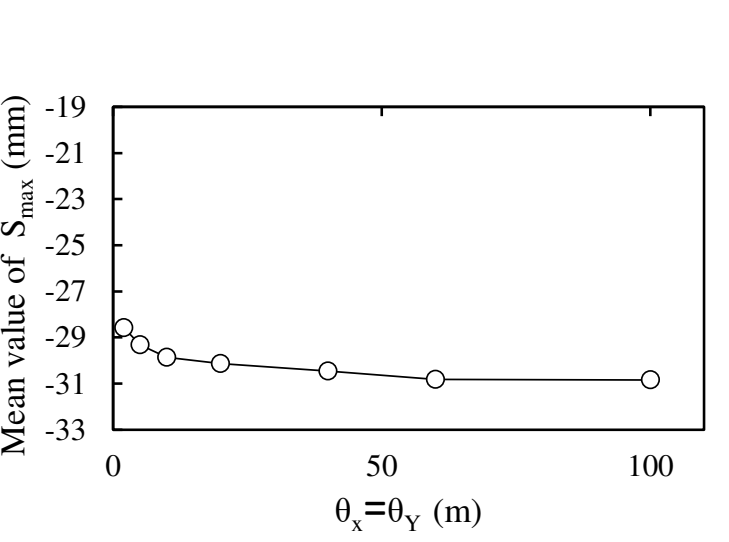

(a)

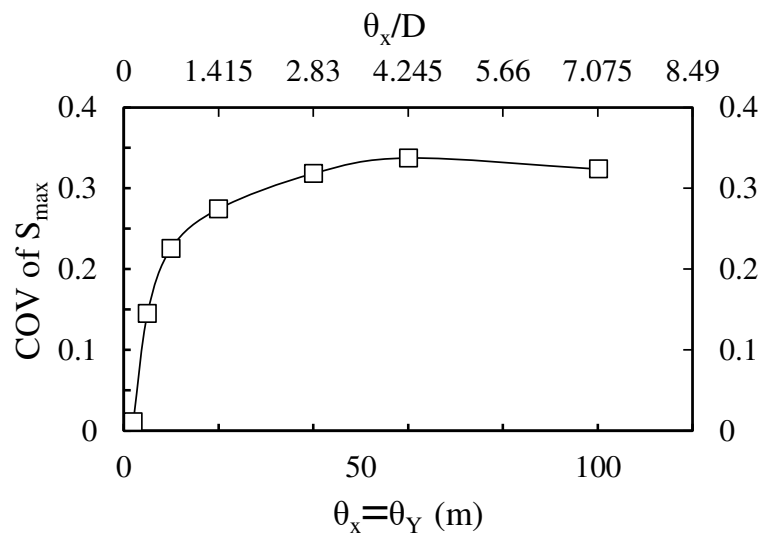

(b)

Fig. 13 Variation of maximum surface settlement $\left(S_{\max }\right)$ statistics with SOF in random fields: a Mean of $S_{\max } ; \mathbf{b}$ COV of $S_{\max }$.

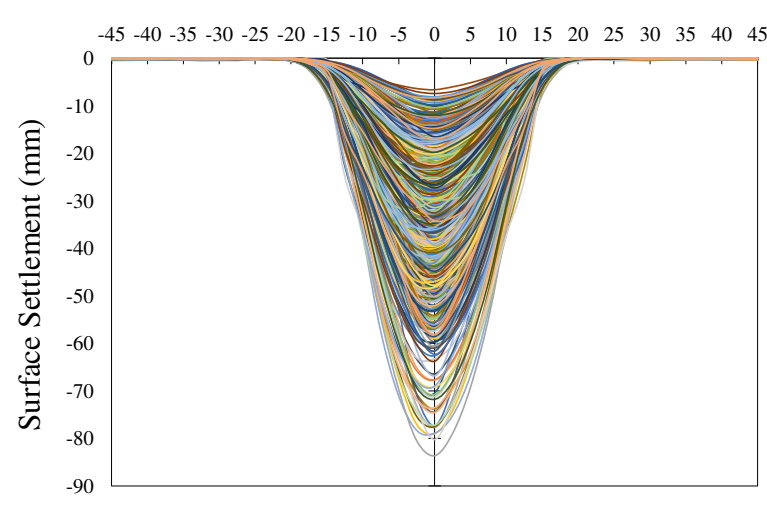

Lateral distance from tunnel axies (m)

(a)

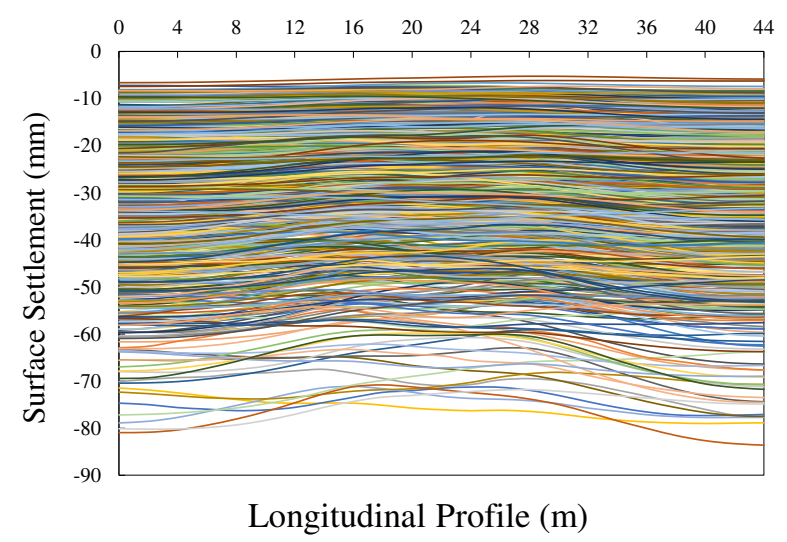

(c)

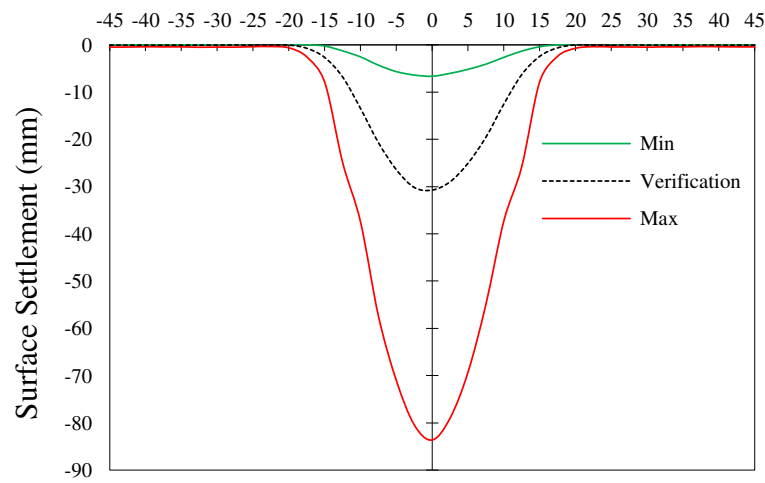

Lateral distance from tunnel axis (m)

(b)

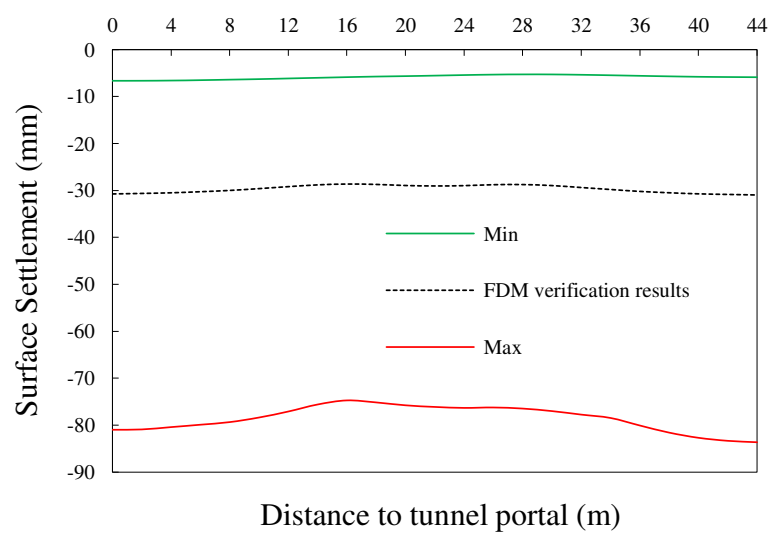

(d) 
Fig. 14 Effects of random field on surface vertical displacement when $\theta_{X}, \theta_{Y}=100 \mathrm{~m}$ a,b Surface settlements based on 1000 runs of MCS c,d Maximum and mini values of surface settlements based on 1000 runs of MCS

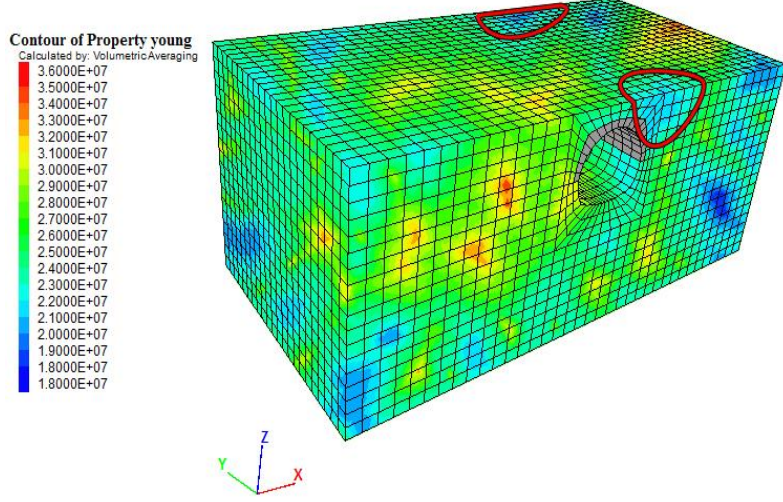

(a)

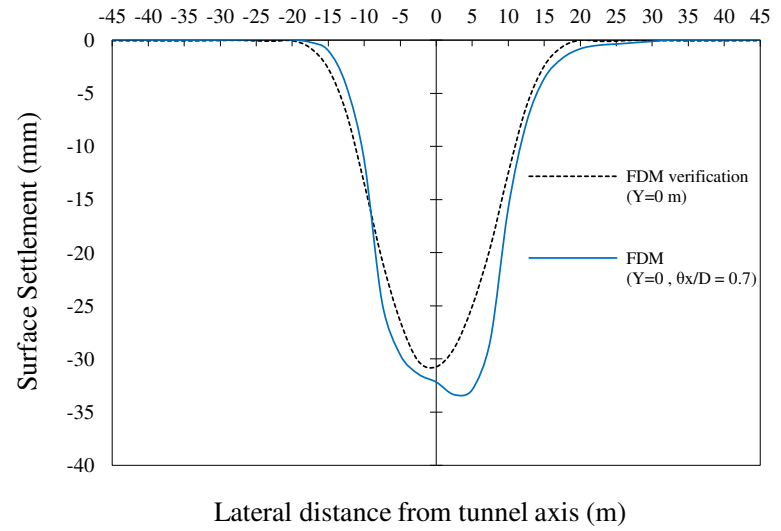

(c)

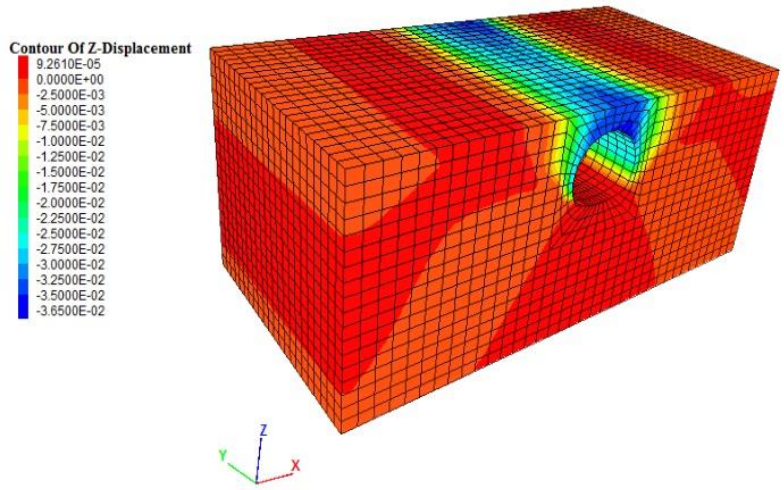

(b)

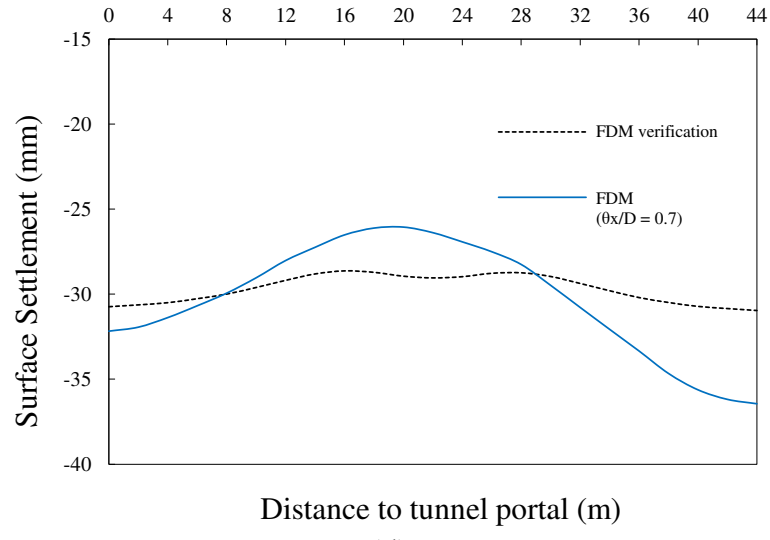

(d)

Fig. 15 The Effects of random field when $\boldsymbol{\theta}_{X} / \boldsymbol{D}=\mathbf{0 . 7}$ a Spatial variability of young's modulus $\mathbf{b}$ Contour of z_displacement $\mathbf{c}, \mathbf{d}$ The surface settlement in cross section and longitudinal profile. 


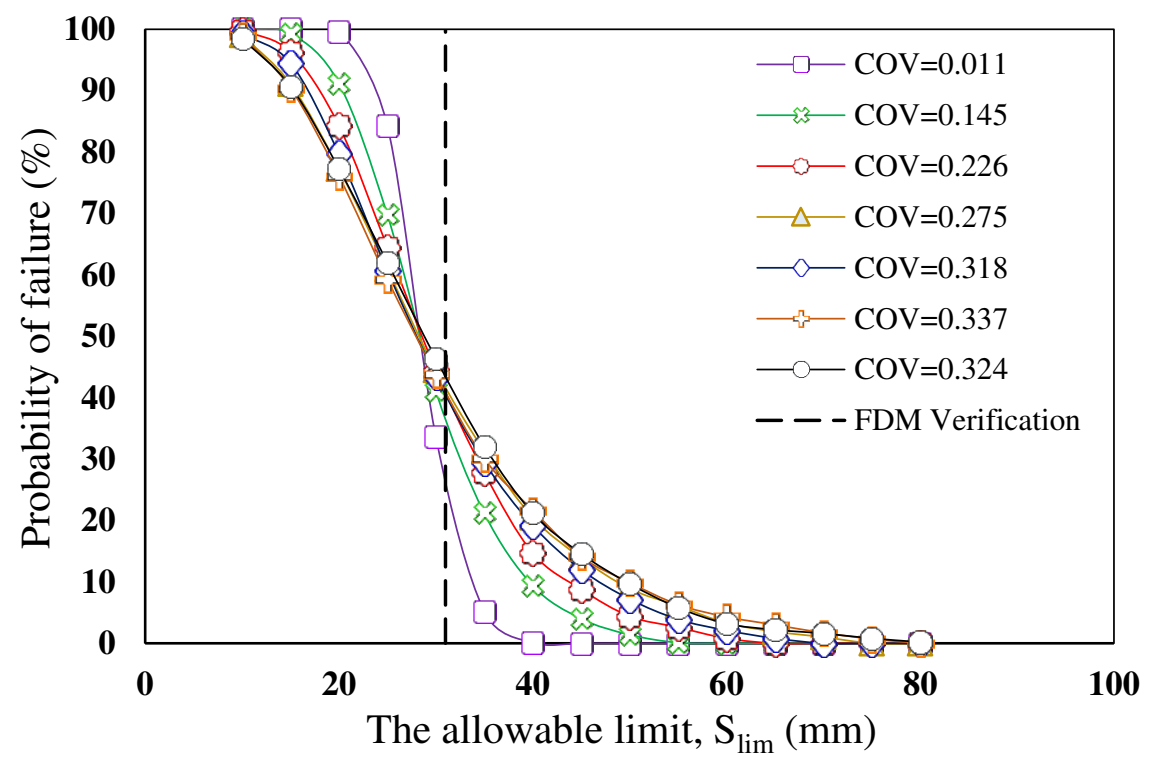

Fig. 16 Probability of failure of the maximal surface settlement exceeding the allowable limit $\left(S_{\text {lim }}\right)$ for various coefficients of variation 